\title{
The Effects of Military Change-of-Station Moves on Spousal Earnings
}

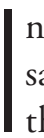
$\mathrm{n}$ the first decade of the 21st century, hundreds of thousands of married individuals served in active-duty roles in the U.S. military. Active duty imposes a unique and often stressful lifestyle on couples and families; even in peacetime, frequent duty location changes can interrupt valued support networks and children's education. Spouses' career earnings may be especially affected by permanent change-of-station (PCS) moves. Job-specific skills and knowledge gained while one is working are essentially lost at the end of that job and must be developed again in a new position. Moreover, spouses seeking work in occupations that require state certification or licensing may face employment barriers if their previous credentials are not recognized at their new location. Finally, the inherently disruptive nature of moving could have negative effects on productivity, thereby lowering wages.

To date, our understanding of how PCS moves affect military spousal earnings has been incomplete. Previous research has focused on outcomes from survey data and comparisons relating current earnings to past moves. These analyses are limited, as previous comparisons could not account for individuals' earnings prior to PCS moves. To understand the full impact that military moves have on spousal earnings, the Office of the Deputy Assistant Secretary of Defense for Military Community and Family Policy asked RAND researchers to tackle the question with a more precise approach.

\section{Methods}

The research team examined the causal impact of military moves on spousal earnings by creating a unique longitudinal database that tracks the careers, incomes, and other information of more than 900,000 military spouses over the period 2001-2012. This database allows for the examination of the effects of PCS moves, controlling for some key observable characteristics of the member and household. More importantly, because the data include information on spousal earnings before and after moves, RAND researchers were able to compare the changes in spousal labor market outcomes in the years surrounding a PCS move to changes that would have been expected if the household had not had a PCS move. To do this, the researchers compared the data of military

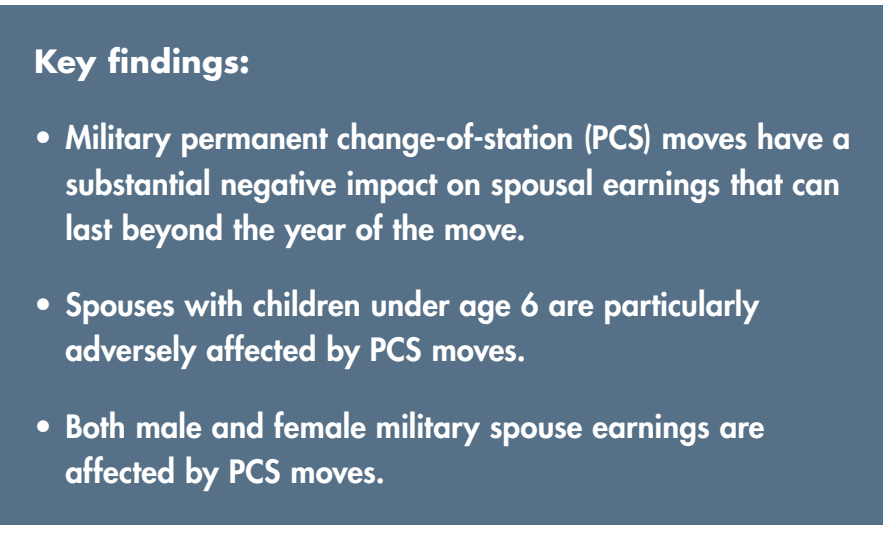

spouses who experienced a PCS move with the data of military spouses who did not move but were similar in other ways, including sex, age, rural or urban location, number and age of children, servicemember rank and education, and many other factors.

\section{Findings}

This study elicited a number of findings, which make clear the economic effects that PCS moves have on military spousal earnings and employment.

PCS moves cause a substantial decline in spousal earnings and labor force participation. Figure 1 shows how military spouses experiencing a PCS move have calendar year earnings that are nearly $\$ 2,100$ less, on average, in the year of the move than spouses not experiencing a PCS move. This estimate, however, averages impacts across both working and nonworking spouses and underestimates the impact for those in the workforce. Among working spouses, PCS moves reduce earnings by approximately $\$ 3,100$, a 14 -percent reduction in average wages for this group.

In addition to reducing earnings, PCS moves also result in lower labor force participation; that is, spouses who experience a PCS move are 4 to 5 percent less likely to have any earnings in the year of the move.

Spouses with children under the age of 6 are particularly adversely impacted by PCS moves. Figure 2 shows how, in the year of the PCS move, spouses with young children 
experience a $\$ 2,600$ reduction in earnings, on average. This accounts for approximately 19 percent of their average earnings, and it is nearly double the $\$ 1,350$ average reduction in earnings experienced by spouses without young children. It is possible that more parental time is needed to help children adapt to the new location or that new job searches are less successful for spouses with caregiving responsibilities.

Female and male military spouse wages and employment are affected by PCS moves. While the vast majority of spouses in the data are female ( 93 percent), male spouses are also negatively impacted by PCS moves. In fact, husbands experience larger dollar losses following a PCS moves than wives $(\$ 3,200$ versus $\$ 2,100)$. However, because male spouses earn more than female spouses on average, their reduction in income following a PCS move represents a smaller proportional reduction in average earnings (12 percent versus 14 percent), as shown in Figure 3.

Negative effects of the PCS move on spousal earnings persist after the move. Figure 4 demonstrates that spouses who experience a PCS move continue to have lower wages several years after the event, though the effects diminish over time. One year after experiencing a PCS move, spouses earn approximately $\$ 1,250$ less (8 percent of average earnings). Two years after the move, spouses earn approximately $\$ 450$ less (3 percent of average earnings). Cumulatively over the three-year period including the year of the move, earnings losses total over $\$ 4,200$, on average.

This is particularly concerning in light of the fact that servicemembers experience PCS moves every two to three years, on average. Just as spouses may be regaining their footing in the labor market, they may experience another PCS move. Figure 5 shows how the PCS move-related earning trend compares with that of individuals with no PCS moves in the same period. Movers experience a drop in earnings in the year of their move, both relative to their own pre-move earnings and relative to the earnings of individuals without PCS moves. Over the next two calendar years, earnings for those with a PCS move in year 0 slowly recover, relative to the earnings of individuals without such moves. The second PCS move, in year 3, further lowers earnings below the levels of nonmovers.

\section{Conclusion and Recommendations}

This study demonstrates the substantial negative impacts of PCS moves on spousal earnings. The analysis supports a potential role for military policy to address the career-related costs of military spouses, as well as the importance of programs and policies aimed at alleviating the transition costs associated with PCS moves for spouses. Recent examples of such initiatives are the Department of Defense's My Career Advancement Accounts program, available to assist some
Figure 1. Impact of PCS Moves on Military Spousal Earnings

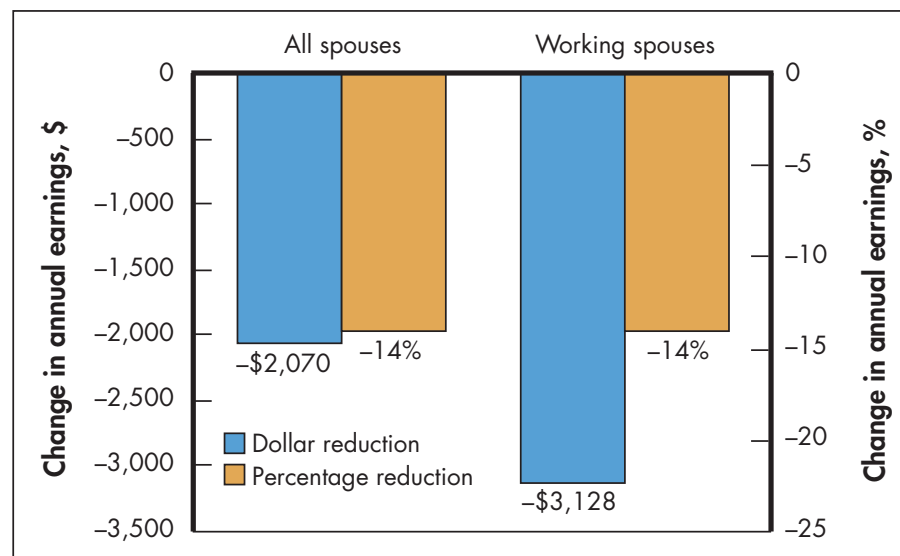

NOTES: The "working spouses" group includes those who had earnings greater than 0 in each year of the study data. Point estimates on reduced earnings are statistically significant at the 1 percent level.

Figure 2. Impact of PCS Moves on Spousal Earnings, by Family Status

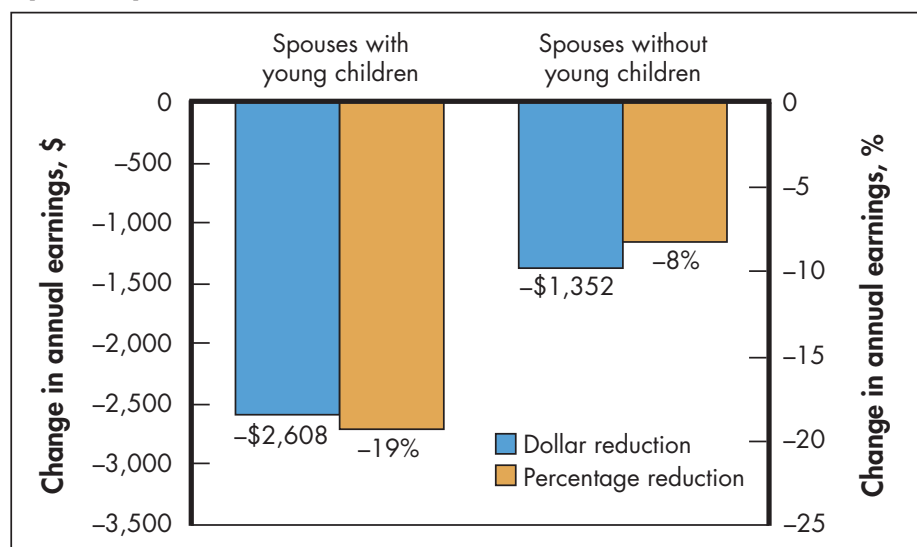

NOTE: Point estimates on reduced earnings are statistically significant at the 1 percent level.

Figure 3. Impact of PCS Moves on Spousal Earnings, by Spouse Gender

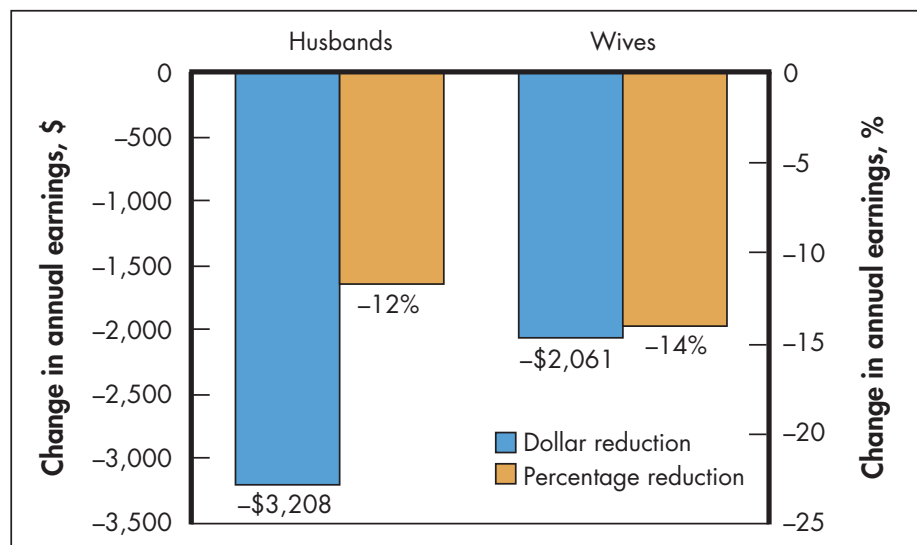

NOTE: Point estimates on reduced earnings are statistically significant at the 1 percent level. 
Figure 4. Persistent Impacts of PCS Moves on Spousal Earnings

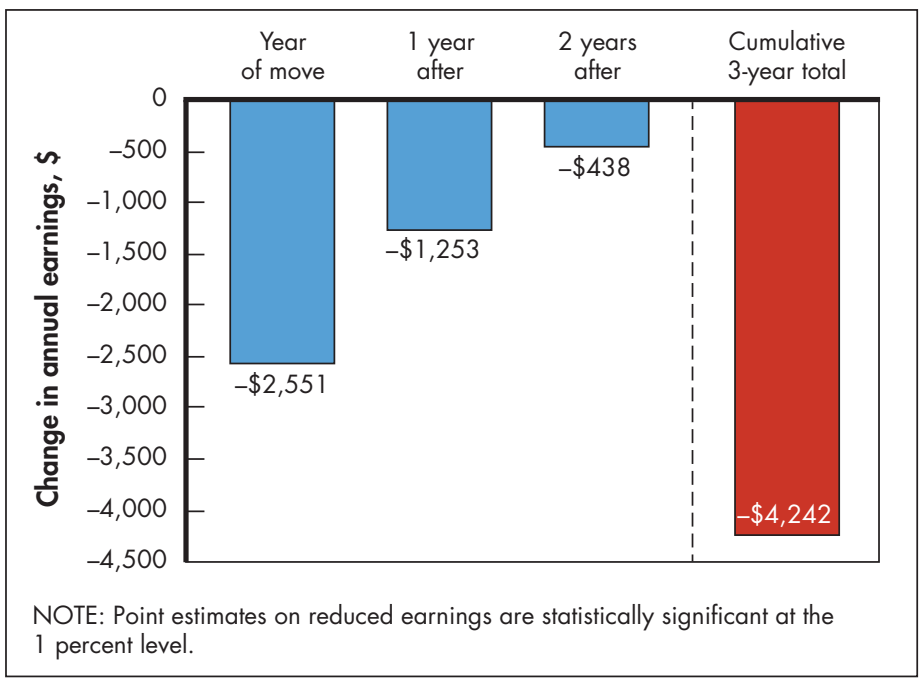

Figure 5. Effects of Repeated PCS Moves on Earnings Growth over Time

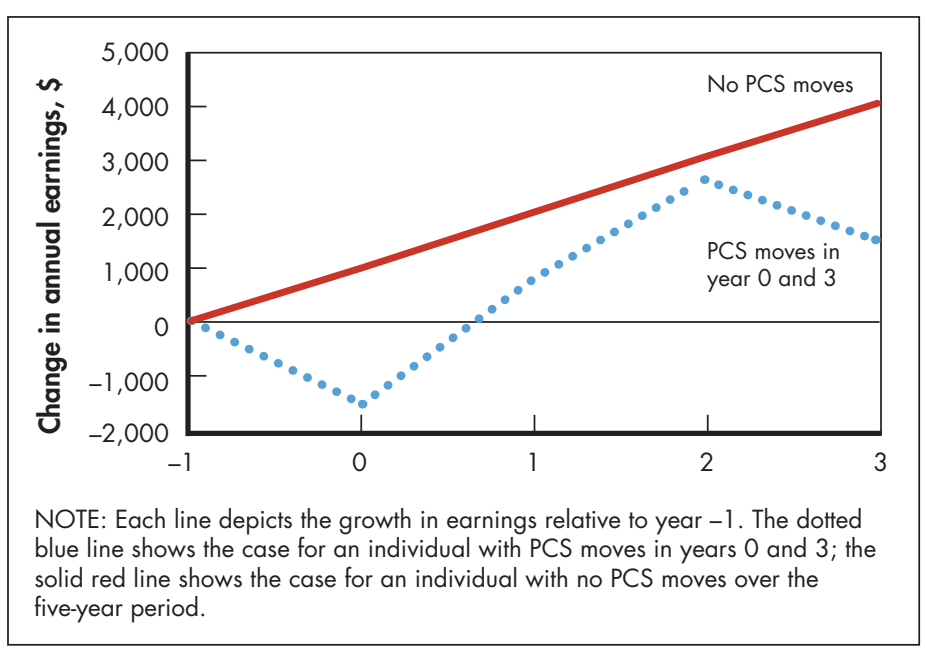

military spouses in acquiring career skills and credentials, and state-level policies that make it possible for spouses to transfer their professional credentials across state lines. To the extent that these interventions are successful, they can have a meaningful impact on the financial well-being of military families. Policymakers may wish to consider programs and policies directed at offsetting PCS move transition costs associated with spouses looking for paid employment or taking time off to set up a new household and develop supportive social networks. Spouses with young children may be the greatest beneficiaries of such efforts, as they experience the largest proportional declines in earnings following a PCS move. This study does not address the cost-effectiveness of relevant military family support policies and programs, however, which should be a consideration of future efforts. Policymakers may also want to reconsider how programs are designed in light of the findings of differential effects in this report.

In particular, the findings that the largest earnings losses are felt by spouses with young children (and by older spouses and spouses of officers) and that male spouses also suffer career harms from PCS moves suggest opportunities for targeting efforts to increase impact. 
This brief describes work done in the RAND National Defense Research Institute and documented in The Effects of Military Change of Station Moves on Spousal Earnings, by Jeremy Burke and Amalia R. Miller, WR-1170-OSD, 2016 (available at www.rand.org/t/WR1170). To view this brief online, visit www.rand.org/t/RB9920. This brief is designed to communicate emerging research to policymakers and the public. Although the working paper on which this brief is based has undergone peer review, the research should be treated as work in progress. Conclusions are preliminary and subject to change. The RAND Corporation is a research organization that develops solutions to public policy challenges to help make communities throughout the world safer and more secure, healthier and more prosperous. RAND is nonprofit, nonpartisan, and committed to the public interest. RAND's publications do not necessarily reflect the opinions of its research clients and sponsors. RAND ${ }^{\circledR}$ is a registered trademark. ๑ RAND 2016

Limited Print and Electronic Distribution Rights: This document and trademark(s) contained herein are protected by law. This representation of RAND intellectual property is provided for noncommercial use only. Unauthorized posting of this publication online is prohibited. Permission is given to duplicate this document for personal use only, as long as it is unaltered and complete. Permission is required from RAND to reproduce, or reuse in another form, any of our research documents for commercial use. For information on reprint and linking permissions, please visit www.rand.org/pubs/permissions.

\section{www.rand.org}

